\title{
STUDI DINAMIKA ROTOR POMPA PENGISI AIR KETEL (BFWP) 6 TINGKAT MENGGUNAKAN PERANGKAT LUNAK
}

\author{
Fatkur Rachmanu \\ Program Studi Teknik Mesin \\ Politeknik Enjinering Indorama \\ Email: fatkur.rachman@gmail.com
}

\begin{abstract}
ABSTRAK
Pompa multi tingkat untuk mengatasi kebutuhan fluida cair agar dapat mengalirkan ke tempat yang elevasinya sangat tinggi atau sangat jauh atau mempunyai perbedaan tekanan terhadap sisi masuk dan keluar pompa yang sangat tinggi. Pompa multi tingkat digunakan sebagai pompa pengisi air ketel (Boiler Feed Water Pump) dengan 6 buah/tingkat baling-baling (impeller) dan di hubungkan dengan kopling menggunakan penggerak mula turbin uap yang mempunyai variasi kecepatan 4000 rpm hingga 6000 rpm. Dengan daya input pompa sebesar 831.050 Watt. Torsi putar untuk putaran $6000 \mathrm{Rpm}$ adalah 1323,33 Nm. Ditopang hydrodynamic bearing di kedua ujung poros. Pada penelitian ini diamati frekuensi pribadi pada poros rotor, menentukan modeshape poros rotor (Critical speed map), respon takseimbang (Unbalance response) pada bearing station. Menggunakan Software- $X$ berupa perhitungan perangkat lunak dinamika rotor dibandingkan dengan software Solidworksmenggunakan metode elemen hingga. Studi dinamika rotor mempunyai kecepatan kritis sebesar 2750 CPM dengan kekakuan bearing $1 \times 10^{6}$ lbf/inchi pada mode 1. Pada mode no.7 akan terjadi simpangan amplitudo yang besar.
\end{abstract}

Kata kunci: dinamika, rotor, pompa, pengisi, ketel, tingkat.

\section{ABSTRACT}

Multi-stages pump to address the needs of liquid fluid that can flow into the elevation is very high or very far or of a different pressure on the pump suction and discharge are very high. Multi-stages pump is used as a filler pump water boiler (Boiler Feed Water Pump) with 6 units / stages propeller (impeller) and is connected with the coupling using a steam turbine prime movers that have variations in the speed of $4000 \mathrm{rpm}$ to $6000 \mathrm{rpm}$. With the pump input power of 831,050 watts. Rotary torque for rotation of $6000 \mathrm{rpm}$ is $1323.33 \mathrm{Nm}$. Sustained hydrodynamic bearings at both ends of the shaft. In this study, the frequency observed personally on the rotor shaft, determines the shape mode (Critical speed map), the response (unbalance response) on a bearing station. Using Software- $X$ is a calculation of rotor dynamics software compared with Solidworks software using the finite element method. Rotor dynamic study has critical velocity of 2750 CPM with bearing stiffness $1 \times 10^{6} \mathrm{lbf} /$ inch in mode 1 . In mode no 7. will occur deviation of large amplitude.

Keywords: dynamic, rotor, pump, feed, boiler, stage,

\section{PENDAHULUAN}

Pada pompa multi tingkat saat berputar akan dapat diamati / dipelajari dinamika rotor pada putaran kritis pompa pengisi air ketel untuk mengetahui keandalan pompa tersebut apakah melewati ambang batas desain atau tidak. Hal teknis yang perlu diperhatikan adalah frekuensi pribadi (natural frequency), modus/ mode lendutan, respon takseimbang (unbalance response).

Frekuensi adalah banyaknya gelombang getaran dalam satu satuan waktu. Unit satuan untuk frekuensi biasanya ditunjukkan dalam satuan cycle persecond (CPS) atau cycle per minute (CPM) ataupun dalam satuan Hertz, dimana nilai 1 CPS sama dengan $1 \mathrm{~Hz}$.

Fase adalah perpindahan atau perubahan posisi pada bagian-bagian yang bergetar secara relatif untuk menentukan titik referensi atau titik awal pada bagian lain yang bergetar pada frekuensi yang sama. Transformasi Fourier cepat (FFT) adalah suatu model transformasi yang memindahkan sinyal domain spasial atau sinyal domain waktu menjadi sinyal domain frekuensi.

Putaran kritis yaitu jika suatu poros yang berputar dan akan bergetar dengan hebat pada satu putaran tertentu. Putaran kritis terjadi pada putaran yang sama dengan frekuensi getaran pribadi /alamiah (natural frequency) dari sistim poros/rotor. Penyebab utama karena ketidak-seimbangan poros (unbalance). Secara praktis/teknis sulit dihindari, bila putaran kerja lebih besar putaran kritis, getaran akan 
teredam/tereduksi akibat keadaan alamiah /seimbang sendiri (self-balanced). Kecepatan / putaran kritis dapat tanpa redaman dan dengan redaman. Bila satu rotor, yang mempunyai eksitasi dinamik, berputar dengan putaran yang sama dengan frekuensi eksitasi (frekuensi alamiah, frekuensi pribadi) maka akan terjadi resonansi yang mengakibatkan timbulnya getaran yang besar.

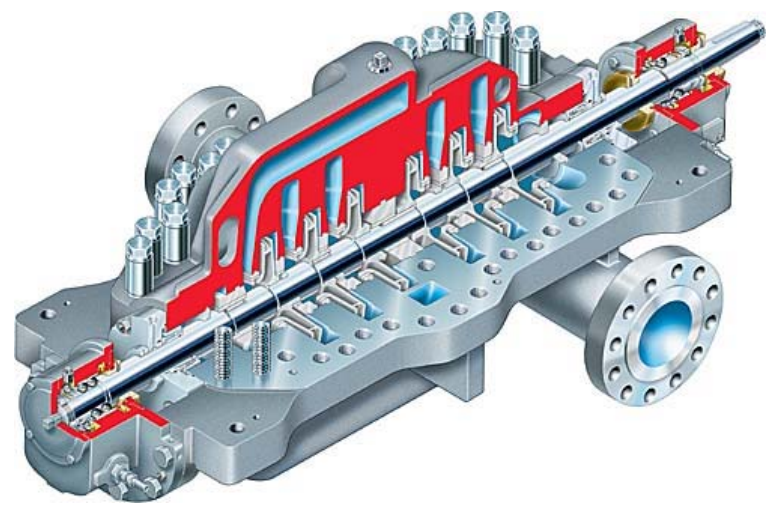

Gambar 1. Pompa Horisontal dengan Impeller 6 Tingkat (API 610 - BB3 Type) [1]

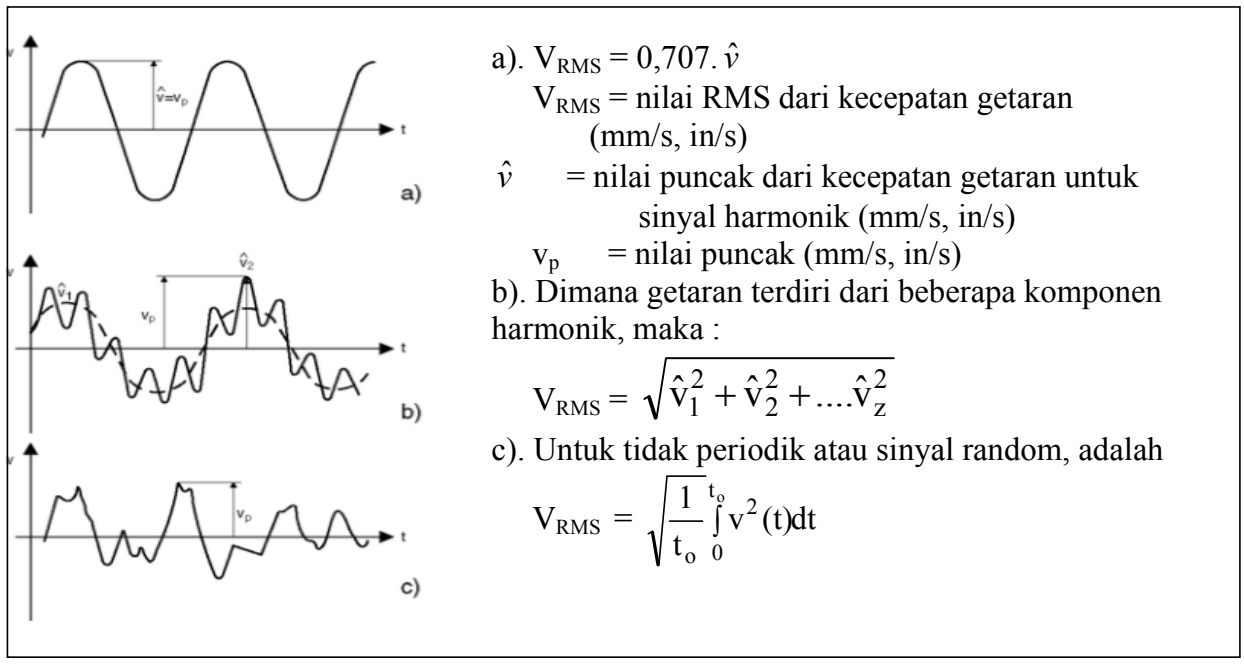

\section{Gambar 2. Kecepatan Getaran Suatu Fungsi Dari Waktu [2]}

Mode/Modus/bentuk lendutan adalah jika putaran atau kecepatan kritis yang berhubungan dengan karakteristik sistim dan getaran yang timbul. Karakteristik sistim akan menyebabkan bentuk beberapa moda getaran. Karakteristik suatu sistim dengan kekakuan bantalan (bearing stiffness).

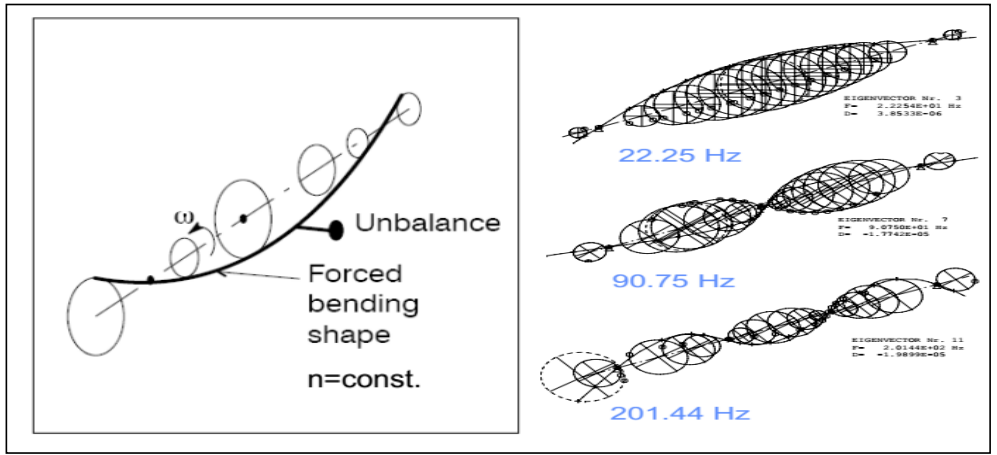

Gambar 3. Bentuk Rotor Berputar Pada Beberapa Mode dan rpm/Frekwensi [3] 


\section{METODOLOGI PENELITIAN}

\subsection{Data Spesifikasi}

Pompa multi tingkat digunakan sebagai pompa pengisi air ketel (Boiler Feed Water Pump/BFWP) dengan 6 buah/tingkat baling-baling (impeller) dan di hubungkan dengan kopling menggunakan penggerak mula turbin uap yang mempunyai variasi kecepatan $4000 \mathrm{rpm}$ hingga $6000 \mathrm{rpm}$. Dengan daya input pompa sebesar 831.050 Watt. Torsi putar untuk putaran $6000 \mathrm{Rpm}$ adalah 1323,33 Nm. Ditopang dengan hydrodynamic bearing di kedua ujung poros. [1-4]. Dalam penelitian ini akan diamati frekuensi pribadi pada poros rotor, Menentukan mode shape poros rotor (Critical speed map ), respon takseimbang (Unbalance response) pada bearing station.

\subsection{Proses Simulasi}

Pada proses simulasi menggunakan perbandingan antara software- $X$ dan Solidworks (FEM simulation)kemudian dibandingkan serta dievaluasi kejadiannya dengan standard, studi literatur pompa. Dalam penelitian ini mempunyai proses alur seperti Gambar 4 seperti dibawah.

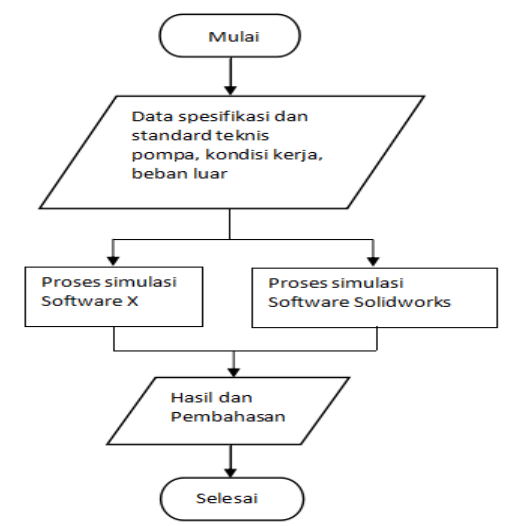

Gambar 4. Diagram Alur Penelitian

\section{HASIL DAN PEMBAHASAN}

Pada hasil simulasi tersebut menggunakan asumsi dan input bahwa material rotor pompa menggunakan baja (steel), dengan skenario kejadian takseimbang (unbalance). Didalam dinamika rotor, masa tak seimbang tidak bisa benar-benar dihilangkan. Kondisi masa tak seimbang disebabkan oleh tidak berimpitnya pusat massa rotor dengan sumbu putarnya, distribusi massa yang tidak seragam terhadap sumbu putar. Ketidakseragaman ini disebabkan oleh material yang tidak homogen, pada saat proses pembuatan (pengecoran dan permesinan), atau karena perakitan (assembly) yang kurang baik [5].

Sistem model terdiri dari 20 element dari poros -rotor impeler , 2 bearing fluida, 7 disc, tanpa redaman, dapat dibuat pada software- $X$ sesuai Gambar 5. dibawah ini.

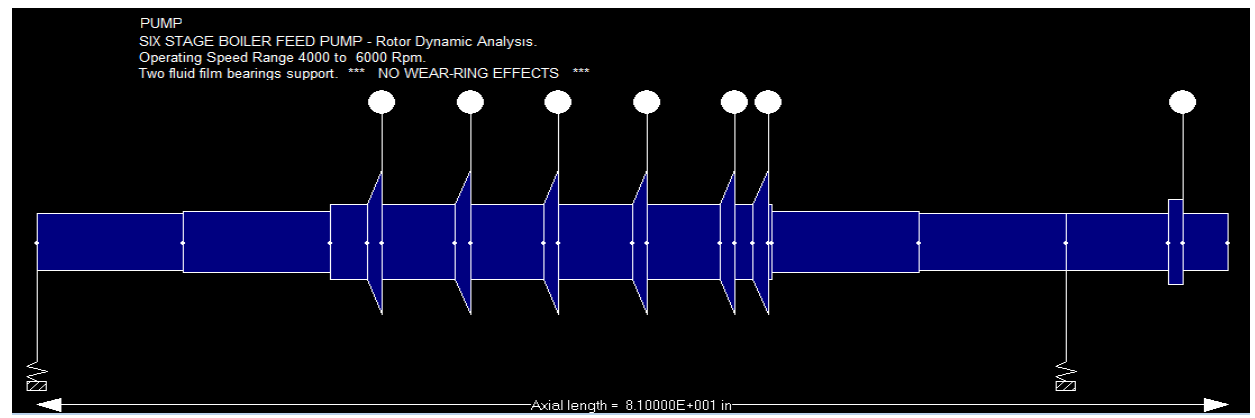

Gambar 5. Skema Model Poros Dan Impeler / Rotor Pompa 
Hasil simulasi komputer dengan Software $-X$ adalah sebagai berikut :

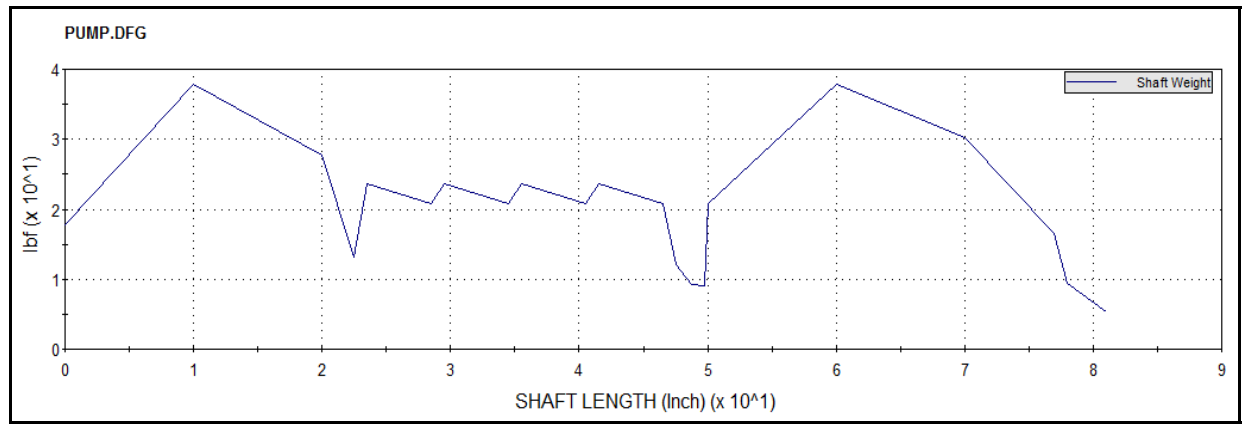

Gambar 6. Grafik Hasil Penimbangan Berat Rotor

Terlihat pada Gambar 6 berupa panjang bentangan dari kiri ke kanan hingga menuju penggerak (turbin uap). Kemudian dapat dilakukan perhitungan defleksi dengan tipe polar pada software- $X$ tersebut menghasilkan Gambar 7a. dan perhitungan defleksi dengan tipe FFT sesuai Gambar 7b.

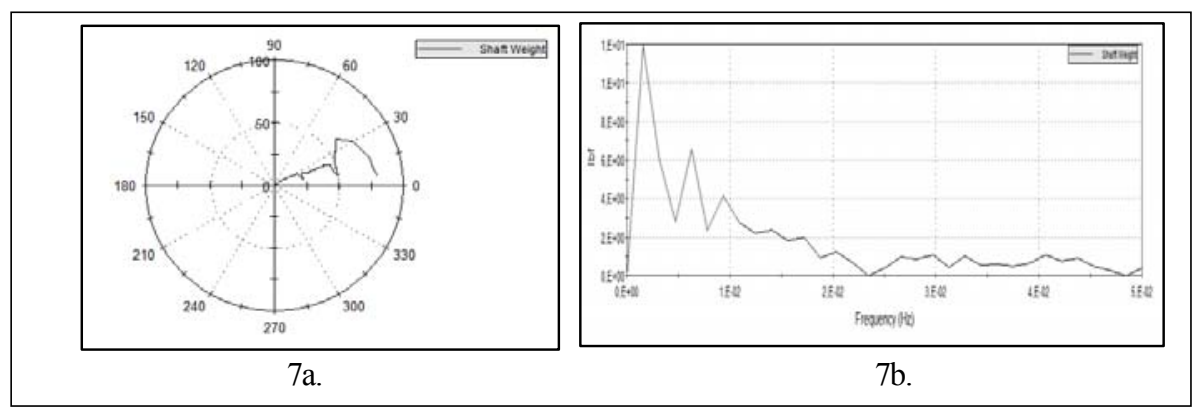

Gambar 7a. Perhitungan Defleksi - Tipe Polar, 7b. Perhitungan Defleksi - Tipe FFT

Kemudian pada software-X memunculkan hasil perhitungan sesuai Gambar 8a. Amplitudo relatif maksimum 1 mils $(\mu \mathrm{m})$ hingga $-0,3$ mils $(\mu \mathrm{m})$ makin menjauh dari penggerak terlihat makin besar penyimpangan terakhir 0,8 mils $(\mu \mathrm{m}$ ) di ujung bearing $N D E$ (non drive end). Pada Gambar $8 \mathrm{~b}$. amplitudo relatif tertinggi 0,6 mils dan menurun hingga mendekati 0

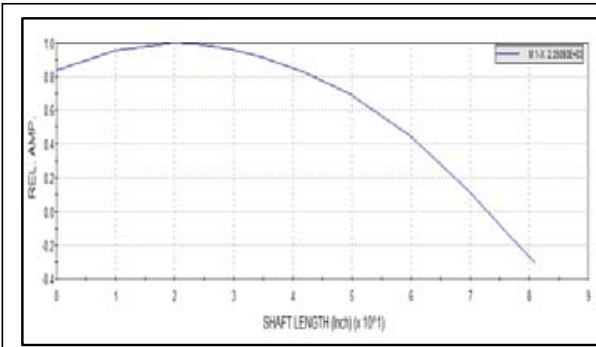

$8 \mathrm{a}$

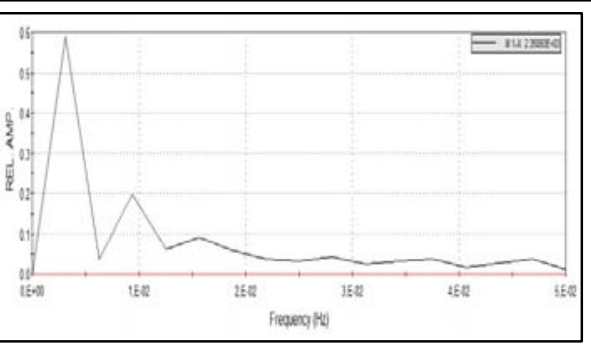

$8 b$.

Gambar 8.a. Mode Shape - tipe garis , 8.b. hasil mode shape - tipe FFT

Adapun hasil perhitungan software-X juga dapat berupa Station Amplitude, phase dan gaya pada bantalan sesuai Gambar 9a dan hasil respon taksembang pada shaft sumbu axis sesuai Gambar 9b. Pada Gambar 9a. terbaca amplitudo 1,7 mils $(\mu \mathrm{m})$, pada $2850 \mathrm{Rpm}$ [2], pada Gambar 9 b. sumbu response takseimbang pada bearing sebesar $\mathrm{Y}$ antara $-0,02$ mils sampai dengan 0,02 mils dan $\mathrm{X}$ antara $-0,025$ sampai 0,025 mils berbentuk oval, sesuai teori literatur pump handbook [2]. 


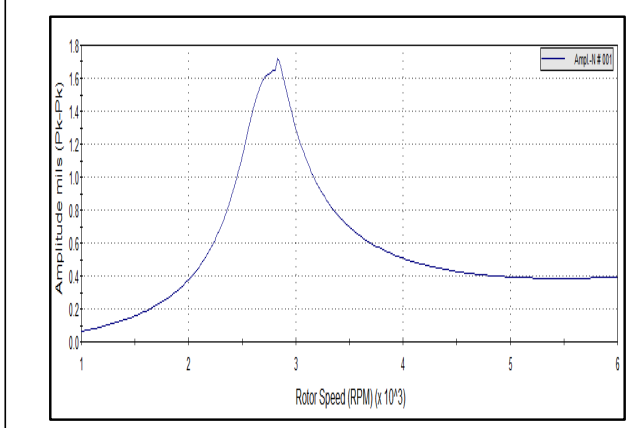

9a.

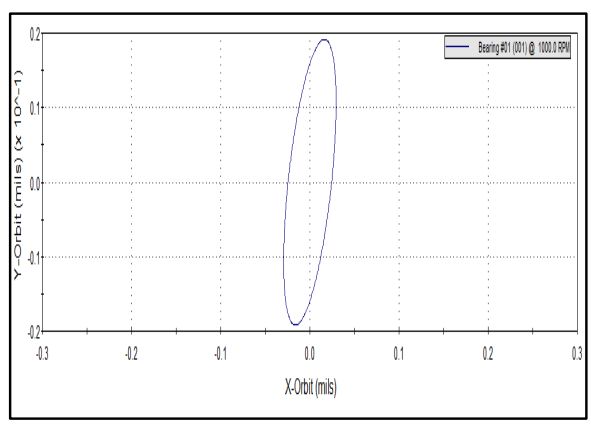

$9 b$.

Gambar 9. Station Amplitude, Phase and Bearing Forces, a. Station Amplitude - Tipe Garis, b. Shaft Axis Unbalance Response

Adapun pada Gambar 10a. Respon orbit takseimbang dilihat dari ujung poros DE (Drive-End). Gambar $10 \mathrm{~b}$. Respon orbit takseimbang maksimum $77 \times 10^{28}$ mils dan menurun hingga muncul terakhir pada $59 \mathrm{hz}$.
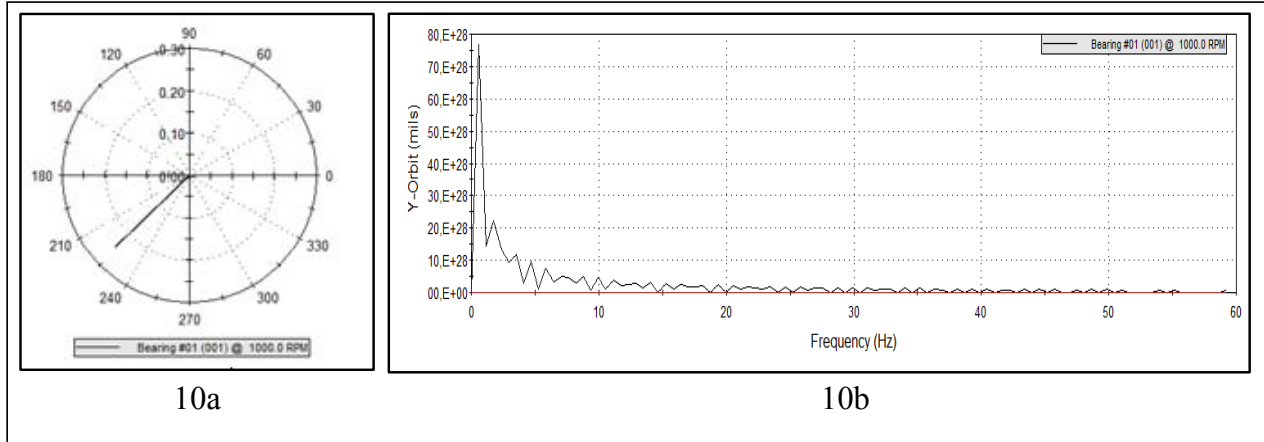

Gambar 10. a. Respon Orbit Takseimbang Pada Bearing Station - Tipe Polar, b. Respon Orbit Masa Takseibang Pada Bearing Station - Tipe FFT

Pada Gambar 11a.terbaca bahwa, respon tak seimbang (unbalance response) puncak-puncak (peakpeak) Sebesar 1,6 mils pada putaran sekitar $2750 \mathrm{Rpm}$ [2]. Pada gambar 11b. terlihat respon waktu dengan amplitudo maksimum adalah $0,125 \times 10^{-2}$ inch dan minimum $-0,025 \times 10^{-2}$ inch.

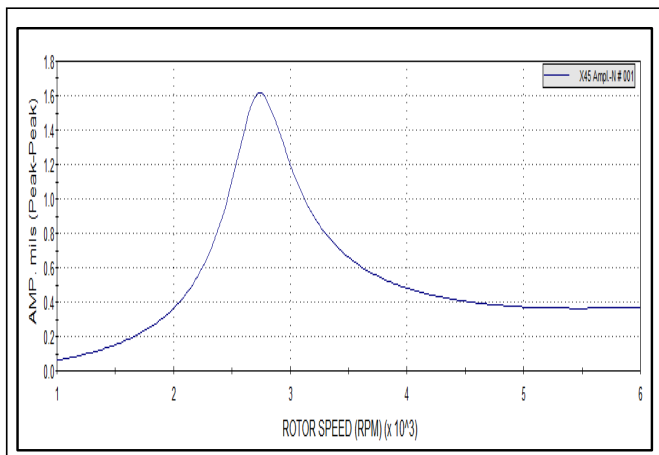

11a.

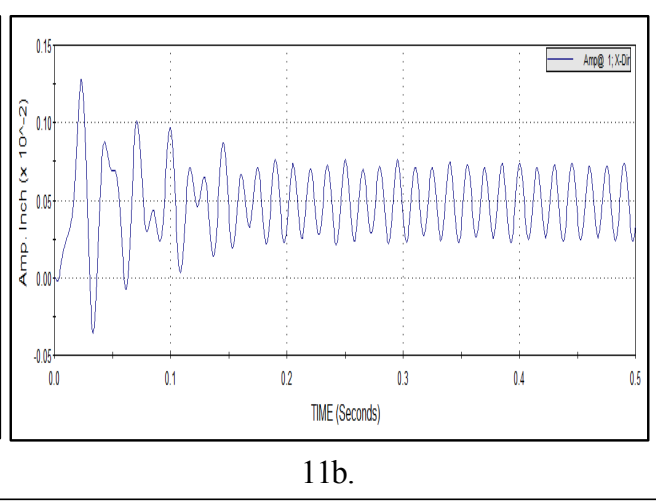

$11 \mathrm{~b}$.

Gambar 11. a. Unbalance Response Probe Amplitudes, b. Time Transien Response - Tipe Garis

Hasil simulasi Software- $X$ dapat menunjukkan Gambar 12. terlihat time transien response Amplitudomaksimum adalah $0,125 \times 10^{-2}$ inch dan minimum -0,025 x $10^{-2}$ inch. Pada Gambar 13. dapat dibuat dengan Software-X berupa kecepatan kritis berbasis FFT. Pada Gambar 14. putaran kritis sebesar 2750 CPM (Rpm) pada kekakuan (stiffness) bearing $1 \times 10^{6} \mathrm{lbf} / \mathrm{in}$ pada mode 1 . Kemudian perhitungan 
Jurnal SIMETRIS, Vol 8 No 1 April 2017

ISSN: 2252-4983

software- $X$ menghasilkan peta kestabilan tipe garis ditunjukkan pada Gambar 15a dan Gambar 15b. tipe FFT.

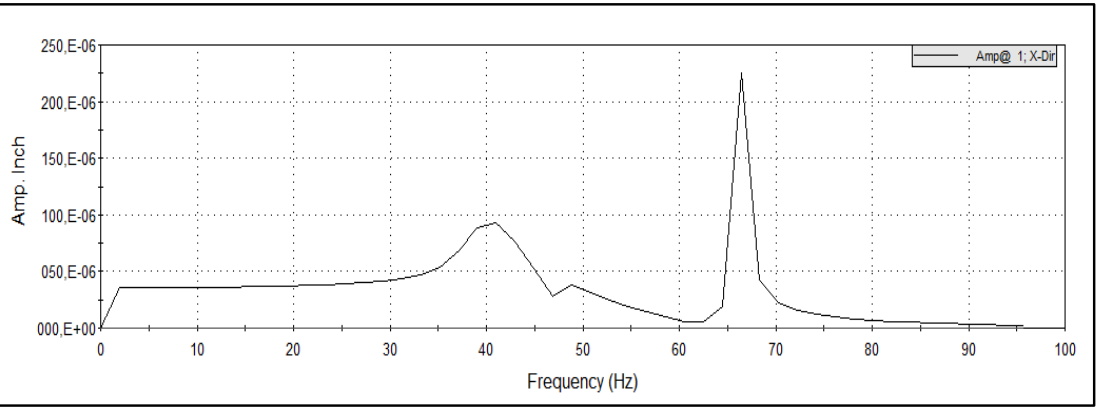

Gambar 12. Time Transient Response - FFT Type

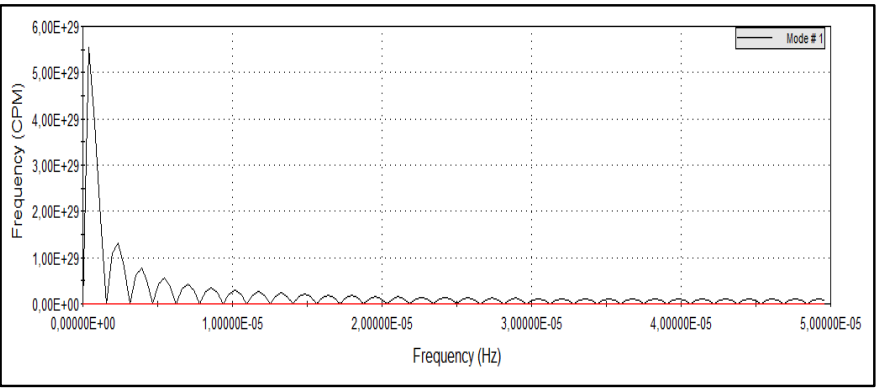

Gambar 13. Critical Speed Map - Tipe FFT

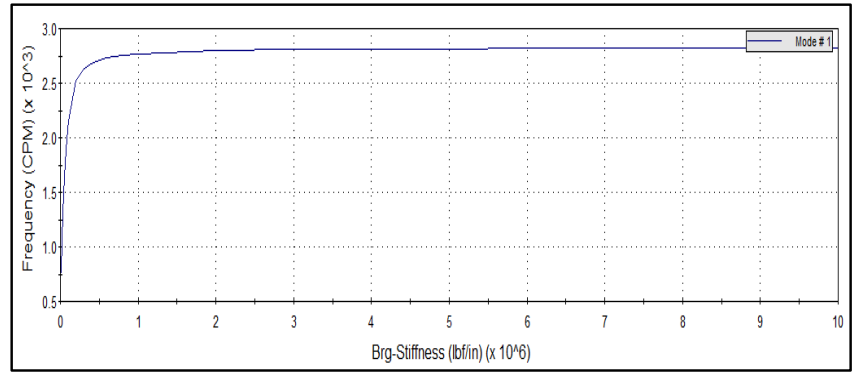

Gambar 14. Simulasi Komputer Putaran Kritis

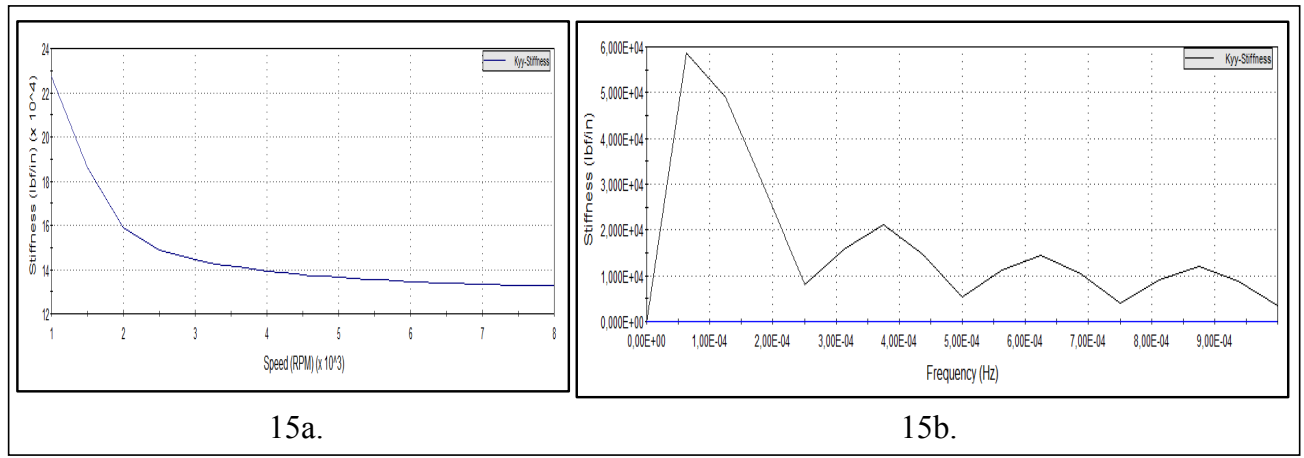

Gambar 15 a. Stability Map - Tipe Garis, b. Stability Map - Tipe FFT 
Dapat terjadi 8 mode pusaran (whirling) dengan tampilan visual 3D, dinamika poros-rotor pompa , dengan shape Amplitudo = 1 , yaitu :

Tabel 1. Mode dan frekuensi hasil software-X

\begin{tabular}{crrr}
\hline Mode & \multicolumn{3}{c}{ Frekuensi } \\
\cline { 2 - 4 } No & $($ Rpm $)$ & Rad/s & \multicolumn{1}{c}{$\boldsymbol{H z}$} \\
\hline 1 & 2350 & 245,09 & 39,167 \\
2 & 2400 & 251,33 & 40,000 \\
3 & 2780 & 291,12 & 46,333 \\
4 & 2900 & 303,69 & 48,333 \\
5 & 7420 & 777,02 & 123,667 \\
6 & 9870 & 1033,58 & 164,500 \\
7 & 11200 & 1172,86 & 186,667 \\
8 & 14200 & 1487,02 & 236,667 \\
\hline
\end{tabular}

Berikut hasil mode/modus getaran rotor dinamik pompa :

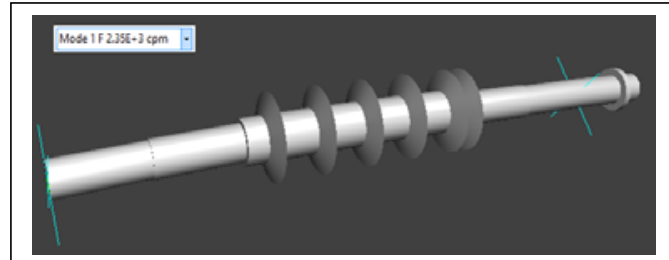

a.

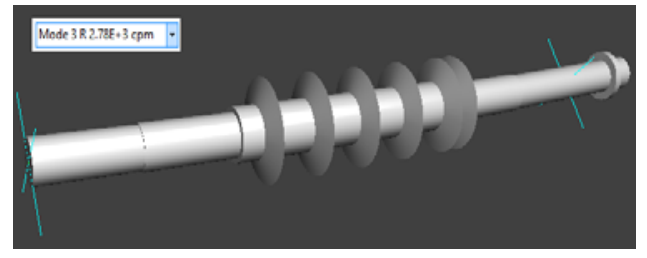

c.

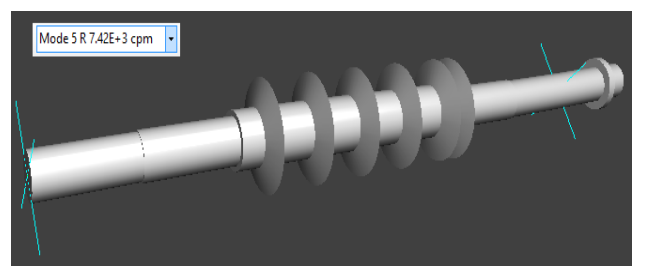

e.

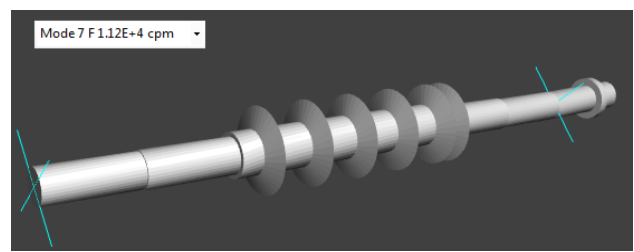

g.

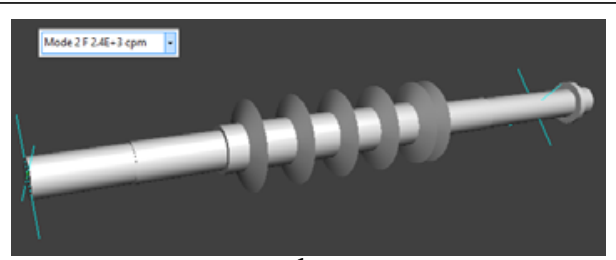

b.

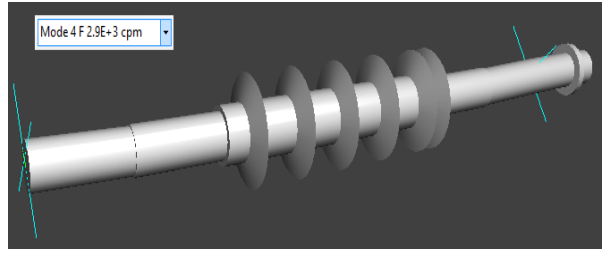

d.

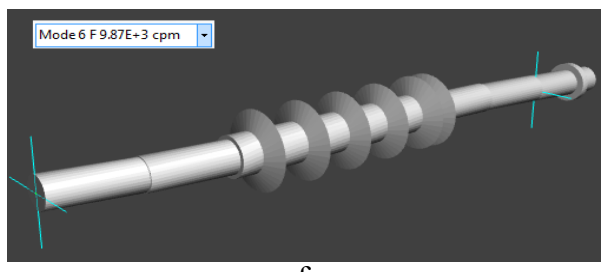

f.

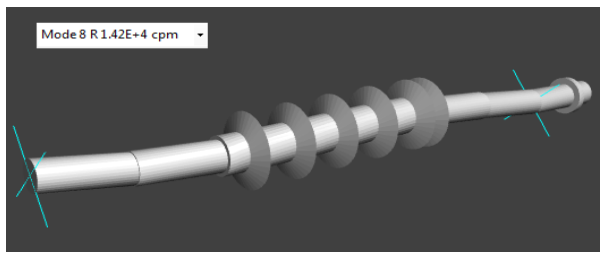

h.

Gambar 16 Hasil simulasi software- $X$ a. Mode $1=2350$ CPM, b. Mode $2=2400$ CPM, c. Mode $3=$ 2780 CPM, d. Mode 4 = 2900 CPM, f. Mode 5 = 7420 CPM, g. Mode $6=9870$ CPM , h. Mode $7=$ 11200 CPM, i. Mode $8=14200$ CPM 
Hasil pre-processing metode elemen hingga (meshing) pada Solidworks adalah sesuai Gambar 17 dibawah ini [6][7]:

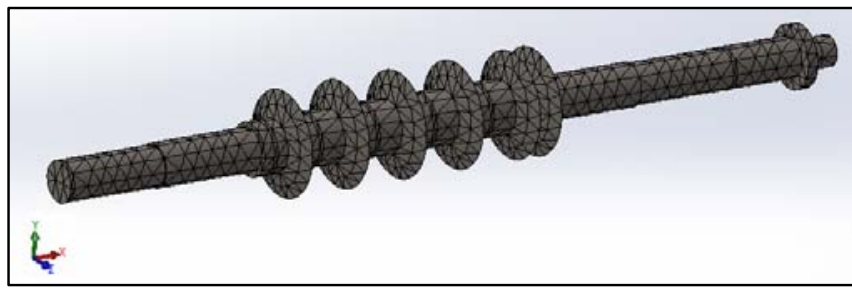

Gambar 17. Proses Meshing pada Solidworks

Tabel 2. Mode dan frekuensi hasil solidworks

\begin{tabular}{crrc}
\hline $\begin{array}{c}\text { Mode } \\
\text { No }\end{array}$ & $\begin{array}{c}\text { Frequency } \\
\text { (Rad/sec) }\end{array}$ & $\begin{array}{c}\text { Frequency } \\
(\boldsymbol{H z})\end{array}$ & $\begin{array}{c}\text { Period } \\
\text { (Second) }\end{array}$ \\
\hline 1 & 777,64 & 123,730 & 0,0080819 \\
2 & 530,61 & 84,449 & 0,0118410 \\
3 & 608,22 & 96,801 & 0,0103300 \\
4 & 692,84 & 110,270 & 0,0090687 \\
5 & 1217,50 & 193,770 & 0,0051608 \\
6 & 1807,10 & 287,610 & 0,0034769 \\
7 & 2686,90 & 427,630 & 0,0023385 \\
8 & 3652,50 & 581,310 & 0,0017203 \\
\hline
\end{tabular}

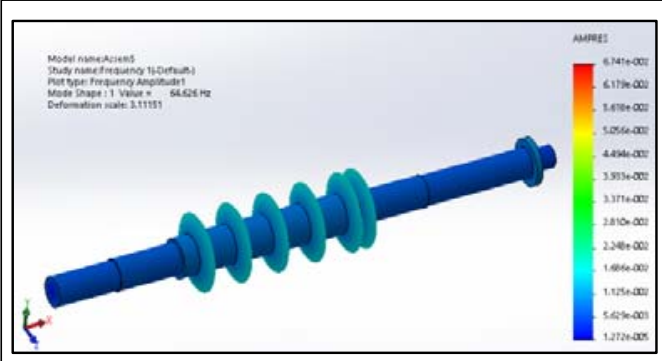

a.

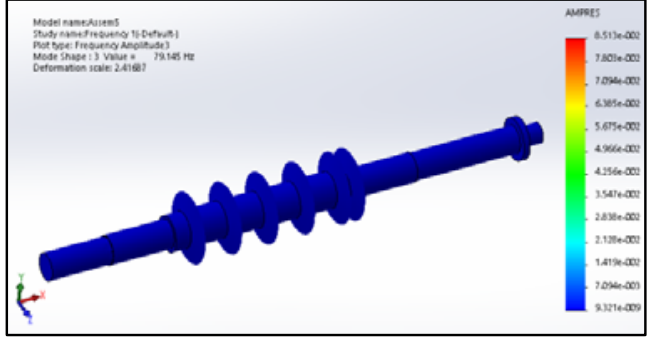

c.

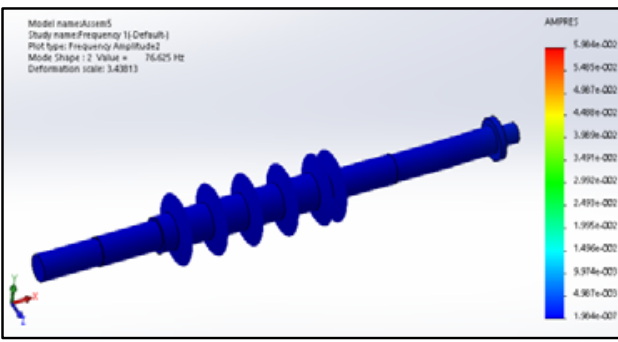

b.

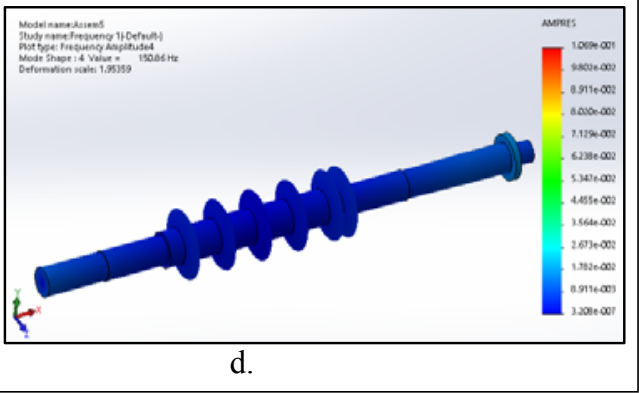

Gambar 18. Hasil simulasi Post-processing metode elemen hingga di Solidworks a. Mode 1, b. Mode 2, c. Mode 3, d. Mode 4. 


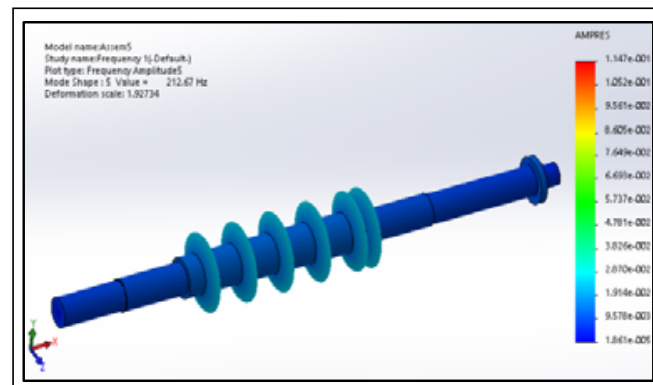

a.

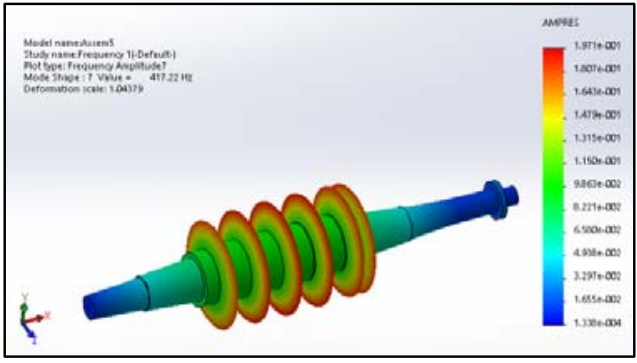

c.

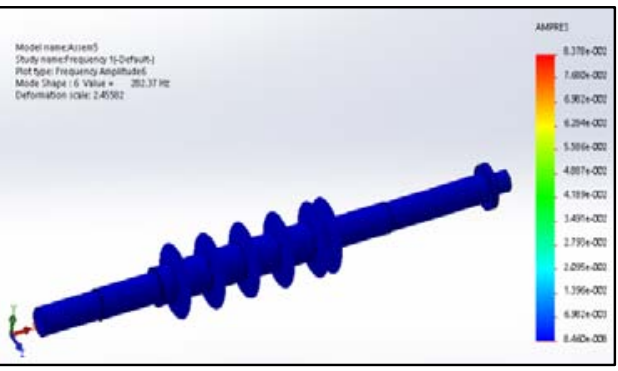

b.

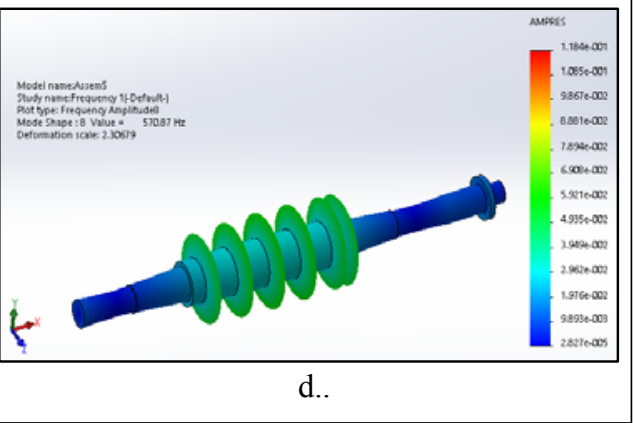

Gambar 19. Hasil Simulasi Solidworks a. Mode 5, b. Mode 6, c. Mode 7, d. Mode 8

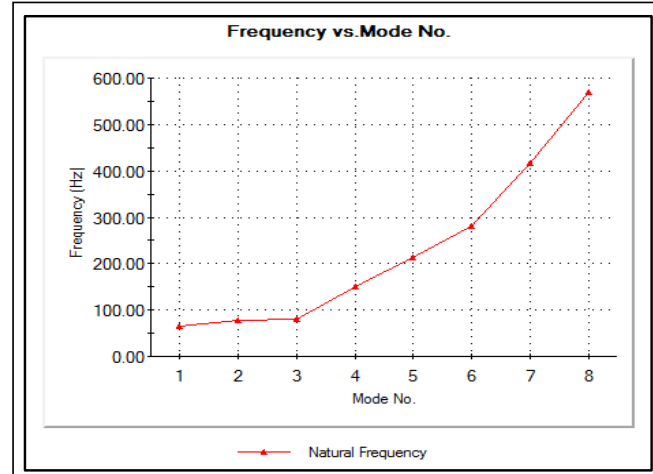

20a.

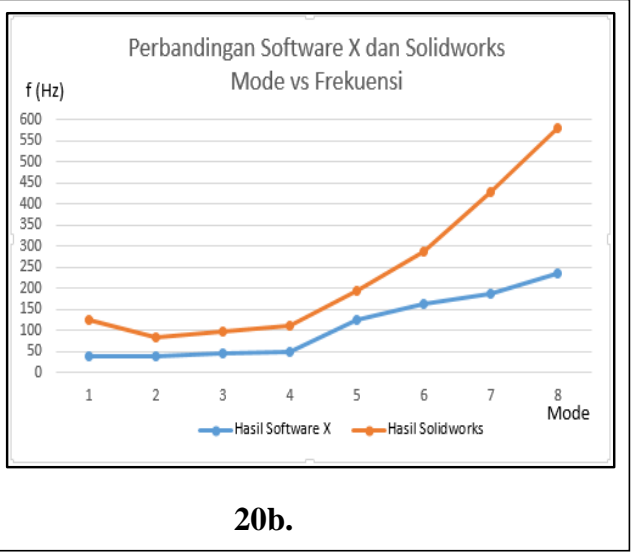

Gambar 20.a. Frekuensi Pribadi vs Mode Hasil Solidworks, 20.b. Perbandingan Software-X dan Solidworksuntuk Frekuuensi Pribadi vs Mode

Pada Gambar 20a. didapat frekuensi pribadi terhadap mode hasil simulasi Solidworks. Pada Gambar 20b. didapat bahwa garis hasil simulasi frekuensi pribadi yang mendekati antara hasil software- $X$ dan Solidworks,akan tetapi pada mode 7 dan 8 terjadi perbedaan.

\section{KESIMPULAN}

1) Dari simulasi komputer kecepatan kritis sebesar 2750 CPM pada bearing stiffness $1 \times 10^{6} \mathrm{lbf} / \mathrm{in}$ pada mode 1.

2) Material impeler pompa dibedakan dengan material poros pompa untuk hasil yang lebih akurat.

3) Perlu diwaspadai ketika rotor berputar saat mode no.7 akan terjadi simpangan amplitudo yang besar.

4) Dibutuhkan perangkat lunak yang mempunyai kejadian mirip dengan sebenarnya sebagai pembanding, serta tetap dibutuhkan percobaan aktual / eksperimen untuk mengetahui hasil prediksi yang lebih presisi.

5) Untuk pompa tipe horizontal in-line injection diperhatikan saat pompa berputar akan terjadi gaya aksial pada poros rotor yang akan menjauhi $(D E)$ motor karena percepatan sudut dari poros rotor sehingga perlu diantisipasi. 


\section{DAFTAR PUSTAKA}

[1] API 610, 2010. Centrifugal Pump for Petroleum, Petrochemical and Natural Gas for Industrries ANSI/API 610 std, $11^{\text {th }}$ Ed, API publishing services, Washington.

[2] Anonim, 2010. Centrifugal Pump Handbook. $3^{\text {rd }}$ ed., Sulzer Pumps Ltd Winterthur, UK.

[3] Germanie, Brian., (2007). Practical Rotor Dynamic for Centrifugal Pump, Sulzer Pump UK Ltd. Calgary: Pump Symposium.

[4] Goulds, (2000), Catalog and Manual Book GPM. Seneca Falls: Gould Pump.

[5] Widodo, Achmad., 2002. "Prediksi Numerik Perilaku Dinamik Sistem Poros Rotor di Industri Dengan Metode Elemen Hingga”. Tesis Magister Teknik Mesin, ITB, 2002

[6] D. Bethune, James. (2015). Enginering Design and Graphics with Solidworks 2015. New York: Prentice-Hall.

[7] S, Harisha. 2014. "Rotor Dynamic Analysis of A Multistage Centrifugal Pump." IJIRSET 3., 1605516063 